\title{
The Pittsburgh G20 Summit
}

udgements on the outcome of international meetings depend largely on what one expects to begin with. Expectations regarding the G20 summit that took place last week in Pittsburgh were not very high; with the crisis apparently over, the window of opportunity for ambitious policies seemed to have closed and many felt that the meeting would revert to routine or concentrate on details. National debates in recent weeks had in fact tended to focus on issues - like the compensation of managers, or the crackdown on tax havens - which are politically appealing but hardly central to the broad issues of international financial reform.

Well, here is the good news: the outcome of the meeting was rather encouraging, and not only because expectations were low. Concrete progress was made on a number of fronts. Unfortunately, it is extremely difficult to extract the substance from the document circulated at the end of the meeting, an astonishingly long and convoluted paper of 24 single spaced pages, probably a record in the annals of international financial cooperation. So, let's try to summarise it, focusing only, for brevity, on (what I regard to be) the three main achievements of the summit.

The first urgent priority facing the leaders was to put the G20 itself on more solid ground. A G20 at ministerial level had existed for ten years already, but its impact had been virtually zero. In spite of its impressive composition (19 industrial and emerging countries plus the European Union, and several other international institutions as observers), the G20 was a political dwarf relative to its smaller but older brother, the G7/G8. In November 2008 a meeting of G20 heads of state and government was summoned in a rush, at the peak of the financial crisis, following the demise of Lehman Brothers and the hasty rescue of AIG. That unusual display of international cohesion helped, or so it seemed, to restore market confidence. The leaders met again in April this year, but once again the meeting seemed ad hoc, without an organisational structure behind it or a well structured follow-up. The credibility and effectiveness of the G20 as a policy actor remained questionable.

Pittsburgh changed this. The leaders decided that the G20 summit would become a regular event, replacing the G7/G8 at the top of the international financial architecture. The "G20 architecture" was given a stronger and more transparent structure: who delivers what, and to whom. The ministers will act as deputies to their leaders, preparing agendas and implementing decisions, supported by two "operational arms": the Financial Stability Board (FSB; the expanded successor of the Financial Stability Forum) and the International Monetary Fund. The former is to be responsible for financial markets, the latter for macroeconomic surveillance and last-resort lending. Both "arms" were strengthened, the former by broadening its representation, the latter by improving its legitimacy through a further quota shift towards emerging nations and also by increasing its financial resources.

So much for institution building and organisation. Regarding substance, the main focus was on financial reform. Work in this area was already underway in many national and international bodies, along three main avenues: enhancing market transparency and accountability (disclosure, accounting standards, market infrastructures, credit ratings), strengthening capital standards and other risk control instruments (capital ratios, liquidity and internal risk management), and improving the authorities' oversight and crisis management capabilities. The key challenge in Pittsburgh was to continue to exert guidance and preserve momentum for reform while at the same time avoiding micro-management and excessive top-down command. Managerial compensation is a prominent example, and a very sensitive one among public opinion. Clearly, compensation structures are an important factor behind the performance of financial systems - in finance monetary incentives 
are all that counts - and, equally clearly, remuneration practices had clearly gone off track in recent years, becoming a contributor to excessive risk-taking. It is unrealistic, however, to think that proper and measured incentives can be imposed by regulation, in finance or elsewhere. They should, rather, stem from responsibility and risk awareness within the appropriate corporate bodies - administrative boards, internal risk control functions, the managers themselves. The primary safeguard must be within the firm. A constant oversight by supervisory authorities should be exercised on the working of all relevant internal corporate bodies.

In this delicate area the leaders seem to have struck a reasonable balance between direct guidance and delegation. On risk control their message was clear - strengthen capitalisation; extend the focus to leverage and liquidity; avoid pro-cyclical regulation - but implementation was left in the experienced (and hopefully speedy) hands of the Basel Committee. A number of broad principles on compensation practices were established, but the task was left to the FSB and especially to national supervisors (which "should have the responsibility to review firms' compensation policies and structures with institutional and systemic risk in mind...") In the key area of moral hazard, the leaders asked for the establishment of bank resolution procedures and standing crisis management groups in all systemically important institutions, especially those operating across borders. On this issue, essential for reducing the "too big to fail" problem that was so pervasive during the crisis, one could perhaps only complain that the deadline for setting up the new resolution regimes was set at end 2010 - too far in the future.

The third, but by no means least important, area where the G20 made useful headway is that of global imbalances. There seems to be increasing consensus after the crisis that large and persistent payments disequilibria among currency areas, most notably between the USA and Asia, were among the contributors to systemic risk-building in the international financial system in the years preceding the crisis. Normally, external imbalances are kept under control by market forces, but this does not happen if there are asymmetries in the international adjustment process - for example, if deficits are financed by money creation, as in the case of the USA, or exchange rates are controlled, as in China. In this case, macroeconomic policies must come to the rescue. On the eve of Pittsburgh it seemed unlikely that leaders would enter this highly contentious territory, where the needs of international coordination collide with national prerogatives. Again, the outcome was better than expected. At the initiative of the USA - and surprisingly without much enthusiasm from Europeans - a "framework" for multilateral surveillance of macroeconomic policies was put in place, with the aim of making national policies ("fiscal, monetary, trade, structural") consistent with balanced growth, including regular consultations on commonly agreed policies and objectives. The IMF was asked to give technical support, working with G20 ministers and central banks, and to report regularly to the G20 leaders. It will be up to the IMF now to ensure that action and substance follows from these commitments.

All in all, on the three most important themes on the table at Pittsburgh (institution building; financial reform; global imbalances) the G20 political leaders have played their part. Concrete implementation, as always, will play a key role in all three areas, so we should not be overly complacent. It will be a long process and there may be setbacks. But the essential foundations of a better financial order than the one we had in August 2007, when the crisis started, are in place. Pittsburgh was a milestone. Let the follow-up work begin.

Ignazio Angeloni

Advisor to the ECB Executive Board and Visiting Scholar, Bruegel Former G20 Finance Deputy 